\title{
Work in Progress: Progress of the NSF RED Revolution
}

\section{Dr. Susan M. Lord, University of San Diego}

Susan M. Lord received a B.S. from Cornell University and the M.S. and Ph.D. from Stanford University. She is currently Professor and Chair of Electrical Engineering at the University of San Diego. Her teaching and research interests include electronics, optoelectronics, materials science, first year engineering courses, feminist and liberative pedagogies, engineering student persistence, and student autonomy. Her research has been sponsored by the National Science Foundation (NSF). Dr. Lord is a fellow of the ASEE and IEEE and is active in the engineering education community including serving as General Co-Chair of the 2006 Frontiers in Education (FIE) Conference, on the FIE Steering Committee, and as President of the IEEE Education Society for 2009-2010. She is an Associate Editor of the IEEE Transactions on Education and the Journal of Engineering Education. She and her coauthors were awarded the 2011 Wickenden Award for the best paper in the Journal of Engineering Education and the 2011 and 2015 Best Paper Awards for the IEEE Transactions on Education. In Spring 2012, Dr. Lord spent a sabbatical at Southeast University in Nanjing, China.

\section{Dr. Beena Sukumaran, Rowan University}

Beena Sukumaran has been on the faculty at Rowan University since 1998 and is currently Professor and President's Fellow. She was Chair of Civil and Environmental Engineering until very recently. Under her leadership, the Civil and Environmental Engineering Program had seen considerable growth in student and faculty numbers. Her area of expertise is in micro-geomechanics and has published over 100 peer reviewed conference and journal papers including several papers on engineering education and the unique undergraduate curriculum at Rowan University, especially the Engineering Clinics. She has been involved in various outreach activities to recruit more women and minorities into engineering and is Program Chair Elect of the Women in Engineering Division of ASEE. She is the recipient of the 2011 New Jersey Section of ASCE Educator of the Year award as well as the 2013 Distinguished Engineering Award from the New Jersey Alliance for Action.

\section{Dr. Ella Lee Ingram, Rose-Hulman Institute of Technology}

Ella L. Ingram is an Associate Professor of Biology and Director of the Center for the Practice and Scholarship of Education at Rose-Hulman Institute of Technology. Her educational research interests include promoting successful change practice of STEM faculty, effective evolution and ecology instruction, and facilitating undergraduate research experiences. Her teaching portfolio includes courses on: nutrition, introductory biology, ecology and environmental studies, evolution, evolutionary medicine, and research practices in science.

\section{Dr. Anthony A. Maciejewski, Colorado State University}

Anthony A. Maciejewski received the BS, MS, and PhD degrees in electrical engineering from Ohio State University, Columbus in 1982, 1984, and 1987, respectively. From 1988 to 2001, he was a professor of electrical and computer engineering at Purdue University, West Lafayette. He is currently a professor and head of the Department of Electrical and Computer Engineering at Colorado State University. He is a fellow of IEEE. A complete vita is available at: http://www.engr.colostate.edu/ $\sim$ aam.

\section{Prof. James D. Sweeney, Oregon State University}

James D. Sweeney is Professor and Head of the School of Chemical, Biological and Environmental Engineering at Oregon State University. He received his Ph.D. and M.S. degrees in Biomedical Engineering from Case Western Reserve University in 1988 and 1983, respectively, and his Sc.B. Engineering degree (Biomedical Engineering) from Brown University in 1979. He is a Fellow of the American Institute for Medical and Biological Engineering and a Senior Member of the Institute of Electrical and Electronics Engineers. 


\section{Prof. Thomas Martin, Virginia Tech}

Tom Martin is a Professor in the Bradley Department of Electrical and Computer Engineering at Virginia Tech, with courtesy appointments in Computer Science and the School of Architecture + Design. He is the co-director of the Virginia Tech E-textiles Lab and the associate director of the Institute for Creativity, Arts, and Technology. He received his Ph.D. in Electrical and Computer Engineering from Carnegie Mellon University and his B.S. in Electrical Engineering from the University of Cincinnati. His research and teaching interests include wearable computing, electronic textiles, and interdisciplinary design teams for pervasive computing. In 2006 he was selected for the National Science Foundation's Presidential Early Career Award for Scientists and Engineers (PECASE) for his research in e-textile-based wearable computing.

\section{Prof. Joseph M. LeDoux, Georgia Institute of Technology}

Joe Le Doux is the Associate Chair for Undergraduate Learning and Experience in the Department of Biomedical Engineering at Georgia Tech and Emory University. Dr. Le Doux's research interests in engineering education focus on problem-solving, socio-cognitive aspects of the flipped and blended learning environments and on inclusive pedagogies.

\section{Dr. Jeremi S. London, Arizona State University, Polytechnic campus}

Dr. Jeremi London is an Assistant Professor of Engineering at Arizona State University in the Polytechnic School. London is a mixed methods researcher with interests in research impact, cyberlearning, and instructional change in STEM Education. Prior to ASU, London worked at the National Science Foundation, GE Healthcare, and Anheuser-Busch. She earned B.S. and M.S. degrees in Industrial Engineering, and a Ph.D. in Engineering Education from Purdue University.

\section{Dr. Noah Salzman, Boise State University}

Noah Salzman is an Assistant Professor at Boise State University, where he is a member of the Electrical and Computer Engineering Department and IDoTeach, a pre-service STEM teacher preparation program. His work focuses on the transition from pre-college to university engineering programs, how exposure to engineering prior to matriculation affects the experiences of engineering students, and engineering in the K-12 classroom. He has worked as a high school science, mathematics, and engineering and technology teacher, as well as several years of electrical and mechanical engineering design experience as a practicing engineer. He received his Bachelor of Science degree in Engineering from Swarthmore College, his Master's of Education degree from the University of Massachusetts, and a Master's of Science in Mechanical Engineering and Doctorate in Engineering Education from Purdue University. 


\title{
WIP: Progress of the NSF RED Revolution
}

\begin{abstract}
The National Science Foundation (NSF) REvolutionizing engineering and computer science Departments (RED) program is an important initiative in engineering education. The goals of RED are to "enable engineering and computer science departments to lead the nation by successfully achieving significant sustainable changes necessary to overcome longstanding issues in their undergraduate programs and educate inclusive communities of engineering and computer science students prepared to solve $21^{\text {st }}$-century challenges.” In 2015, six RED projects were funded followed by seven in 2016 and six more in 2017, bringing the total number of projects to 19. In addition, NSF funded REDPAR (RED Participatory Action Research), the collaborative effort between researchers at Rose-Hulman and the University of Washington to facilitate communication and collaboration among the RED teams and to study the processes followed by RED teams. This work in progress provides a brief overview of the program and current progress of some projects. We highlight the diversity of current RED projects through updates from eight projects across the three cohorts: four from Cohort 1: Arizona State University, Colorado State University, Oregon State University, and the University of San Diego, three from Cohort 2: Boise State University, Rowan University, Virginia Tech, and one from Cohort 3: Georgia Tech. Updates are also included from the REDPAR team about the RED Consortium (REDCON) and research that crosses the consortium. We hope that this paper will help the engineering education community to learn how these projects are changing the landscape of engineering education in the USA and consider approaches for enacting change on other campuses.
\end{abstract}

\section{Revolutionizing Engineering and Computer Science Departments (RED)} An introduction to the National Science Foundation (NSF)'s IUSE/PFE: REvolutionizing engineering and computer science Departments (IUSE/PFE: RED) program, the conditions that led to it, and an overview of the program as of 2017 is provided in [1]. The goals of IUSE/PFE: RED (hereinafter referred to as RED) are to "enable engineering and computer science departments to lead the nation by successfully achieving significant sustainable changes necessary to overcome longstanding issues in their undergraduate programs and educate inclusive communities of engineering and computer science students prepared to solve $21^{\text {st }}$ century challenges.” Note the focus on department-level reform, which led to the requirement that a department head or dean be the principal investigator. In addition, all RED teams are required to have a social scientist with expertise in change models and an engineering or computer science education researcher with knowledge of current best practices.

As described by current RED program officer, Julie Martin, “The pedagogy itself isn’t the change RED teams are trying to make-pedagogy is one marker of the change. The change shows up in the pedagogy, as well as in many other forms. We're starting to see other markers of change in RED project ideas at the awardee institutions. For example, in faculty position descriptions, expectations outlined in hiring letters, and tenure and promotion policies. These revolutionary changes that RED awardees are making at their institutions is what will allow them to be exemplars of change for the entire engineering education community."[2] 


\section{Funded RED projects}

In 2015, the first cohort of six RED projects were funded at Arizona State University (ASU), Colorado State University (CSU), Oregon State University (OSU), Purdue University, University of North Carolina, Charlotte (UNCC) and the University of San Diego (USD). In 2016, the second cohort of seven more projects were funded at Boise State University, Iowa State University, Rowan University, University of Illinois, University of New Mexico, University of Texas at El Paso, and Virginia Tech. In 2017, the third cohort of six additional projects were funded at Clemson University, East Carolina State University (ECU), Georgia Tech, Texas A\&M, North Carolina A\&T and Seattle University. In addition, NSF funded researchers at Rose-Hulman and the University of Washington (called REvolutionizing engineering and computer science Departments Participatory Action Research REDPAR) to facilitate communication and collaboration among the RED teams and to study the processes followed by RED teams.

All projects funded between 2015 and 2017 in the RED program are listed in Table 1 including cohort, title, institution, and department. All are public universities except for USD and Seattle University. North Carolina A\&T is an Historically Black College and University (HBCU). UTEP and University of New Mexico are Hispanic Serving Institutions (HSIs). Brief summaries of some of these projects and references to other published work are included in the discussion below.

Table 1 Funded RED Programs from Cohorts 1, 2, and 3.

\begin{tabular}{|c|c|c|c|}
\hline Cohort & $\begin{array}{c}\text { Title } \\
\end{array}$ & Institution & Department \\
\hline 1 & $\begin{array}{l}\text { Additive Innovation: An Educational } \\
\text { Ecosystem of Making \& Risk Taking }\end{array}$ & $\begin{array}{l}\text { Arizona State } \\
\text { University }\end{array}$ & Engineering \\
\hline 1 & $\begin{array}{c}\text { Revolutionizing Roles to Reimagine } \\
\text { Integrated Systems of Engineering } \\
\text { Formation }\end{array}$ & $\begin{array}{l}\text { Colorado State } \\
\text { University }\end{array}$ & $\begin{array}{l}\text { Electrical and } \\
\text { Computer Engineering } \\
\text { (ECE) }\end{array}$ \\
\hline 1 & $\begin{array}{l}\text { Shifting Department Culture to Re- } \\
\text { situate Learning and Instruction }\end{array}$ & $\begin{array}{l}\text { Oregon State } \\
\text { University }\end{array}$ & $\begin{array}{l}\text { Chemical, Biological \& } \\
\text { Environmental } \\
\text { Engineering } \\
\end{array}$ \\
\hline 1 & $\begin{array}{c}\text { An Engineering Education Skunkworks to } \\
\text { Spark Departmental Revolution }\end{array}$ & $\begin{array}{l}\text { Purdue } \\
\text { University }\end{array}$ & $\begin{array}{c}\text { Mechanical } \\
\text { Engineering (ME) }\end{array}$ \\
\hline 1 & $\begin{array}{c}\text { The Connected Learner: Design } \\
\text { Patterns for Transforming Computing } \\
\text { and Informatics Education }\end{array}$ & $\begin{array}{l}\text { University of } \\
\text { North Carolina, } \\
\text { Charlotte }\end{array}$ & Computer Science (CS) \\
\hline 1 & Developing Changemaking Engineers & $\begin{array}{l}\text { University of San } \\
\text { Diego }\end{array}$ & School of Engineering \\
\hline 2 & $\begin{array}{c}\text { Computer Science Professionals } \\
\text { Hatchery }\end{array}$ & $\begin{array}{l}\text { Boise State } \\
\text { University }\end{array}$ & CS \\
\hline 2 & $\begin{array}{c}\text { Reinventing the Instructional and } \\
\text { Departmental Enterprise to Advance the } \\
\text { Professional Formation of Electrical and } \\
\text { Computer Engineers }\end{array}$ & $\begin{array}{l}\text { Iowa State } \\
\text { University }\end{array}$ & ECE \\
\hline
\end{tabular}




\begin{tabular}{|c|c|c|c|}
\hline 2 & $\begin{array}{l}\text { Revolutionizing Engineering Diversity } \\
\text { (RevED) }\end{array}$ & $\begin{array}{l}\text { Rowan } \\
\text { University }\end{array}$ & $\begin{array}{l}\text { Civil \& Environmental } \\
\text { Engineering }\end{array}$ \\
\hline 2 & $\begin{array}{l}\text { Defining the Frontiers of Bioengineering } \\
\text { Education at Illinois \& Beyond }\end{array}$ & $\begin{array}{l}\text { University of } \\
\text { Illinois at } \\
\text { Urbana- } \\
\text { Champaign }\end{array}$ & Bioengineering \\
\hline 2 & $\begin{array}{l}\text { Formation of Accomplished Chemical } \\
\text { Engineers for Transforming Society }\end{array}$ & $\begin{array}{l}\text { University of } \\
\text { New Mexico }\end{array}$ & $\begin{array}{l}\text { Chem \& Bio } \\
\text { Engineering }\end{array}$ \\
\hline 2 & $\begin{array}{l}\text { A Model of Change for Preparing a New } \\
\text { Generation for Professional Practice in } \\
\text { Computer Science }\end{array}$ & $\begin{array}{l}\text { University of } \\
\text { Texas at El Paso }\end{array}$ & CS \\
\hline 2 & $\begin{array}{l}\text { Radically Expanding Pathways in the } \\
\text { Professional Formation of Engineers }\end{array}$ & Virginia Tech & ECE \\
\hline 3 & $\begin{array}{l}\text { Clemson University: Learning Teams } \\
\text { and Innovation Ventures for Adaptable } \\
\text { Training in Engineering (CULTIVATE) }\end{array}$ & $\begin{array}{l}\text { Clemson } \\
\text { University }\end{array}$ & Civil \\
\hline 3 & $\begin{array}{c}\text { PPSE - Programmers to Professional } \\
\text { Software Engineers }\end{array}$ & $\begin{array}{l}\text { East Carolina } \\
\text { University }\end{array}$ & Computer Science \\
\hline 3 & $\begin{array}{l}\text { Transforming for inclusion: fostering } \\
\text { belonging and uniqueness in engineering } \\
\text { education and practice }\end{array}$ & Georgia Tech & $\begin{array}{l}\text { Biomedical } \\
\text { Engineering }\end{array}$ \\
\hline 3 & $\begin{array}{l}\text { A Revolution in Engineering Education } \\
\text { Motivated by Needs and Designs }\end{array}$ & $\begin{array}{l}\text { North Carolina } \\
\text { A\&T }\end{array}$ & Chem/Bio Eng \\
\hline 3 & $\begin{array}{l}\text { Revolutionizing through a focus on } \\
\text { identity }\end{array}$ & $\begin{array}{l}\text { Seattle } \\
\text { University }\end{array}$ & $\mathrm{ME}$ \\
\hline 3 & $\begin{array}{l}\text { REvolutionizing Diversity Of } \\
\text { Engineering (REDO-E) }\end{array}$ & Texas A\&M & AeroE \\
\hline
\end{tabular}

\section{Cohort 1}

At Arizona State University, the RED team is taking a systems approach to better understand the educational ecosystem and to support faculty to realize a mindset of additive innovation [3] and pedagogical risk-taking in their classrooms [4].s The team's multi-pronged approach includes understanding the engineering program's current culture through experience-centered narrative research [5], developing an instrument to assess pedagogical risk-taking, developing an understanding of making in the engineering classroom, and tracing impacts of the RED project on other institutions. The team also developed a conceptual framework that leverages previous work in organizational change theory, higher education, and STEM teaching practices [6, 7, 8, 9, $10,11]$ to screen potential faculty interventions to increase the likelihood of success. This 
framework has facilitated the emergence of faculty-driven affinity groups that will serve as one vehicle for increasing pedagogical risk-taking among faculty. The development of other mechanisms to spur additive innovation and pedagogical risk-taking are also underway.

At Colorado State University (CSU), a team of educators are working to overcome the failings of the current engineering educational system by reimagining the roles that faculty play in the teaching and learning environment within the Department of Electrical and Computer Engineering (ECE). The team is implementing a new pedagogical and organizational model where the curriculum is no longer treated as a set of disparate courses taught in unconnected pieces, but as an integrated system that fosters collaboration among faculty and students [12, 13, $14,15]$. Calling for a holistic view of the ECE degree, the team's approach is novel because they are, in effect, throwing away courses, yet their vision can be realized within the structural barriers inherent in higher education. Technical content that is deemed fundamental to an electrical engineering degree is identified and packaged into "Learning Studio Modules" that focus on active learning [16]. Periodic "Knowledge Integration" activities, designed by a faculty integration specialist in collaboration with the technical content faculty, show students why they are learning material and why it matters to the world outside the classroom $[17,18]$. Interwoven throughout the four years of the curriculum are thematic content threads, each led by a faculty "champion". The "Foundations" thread focuses on math and science concepts that are fundamental to electrical engineers [19], the "Creativity" thread promotes innovation through research experiences and individual/group projects [20], and the "Professionalism" thread makes sure that non-technical skills that are critical to an engineer's success are continuously developed throughout their time at CSU [21, 22]. While still early in the implementation phase, preliminary results from the junior-year curriculum (the first to be changed) are very promising. In addition to positive anecdotal comments, the number of students that had to repeat the junior year, i.e., they received a grade of D or F, or withdrew, was cut in half compared to before the RED revolution.

At Oregon State University, the RED team is working to transform a School of Chemical, Biological, and Environmental Engineering (CBEE) [23]. OSU CBEE aspires to building a more inclusive, and professionally-based learning environment for both domestic and international students that better facilitates their understanding of and skills to grow and thrive in the world of engineering culture and practice. Simultaneously, the School is working to bring about change through establishing a culture of inclusion and a shift in student learning environments from highly sequestered activities to more realistic and consequential work that is more typical of the engineering workplace. In this third year of project work at OSU the focus is on: (1) broadened faculty training and engagement in implementation of curricular redesign in a number of studio classes to include more realistic, consequential work via the pedagogy of model-eliciting activities [24]; (2) establishing a faculty and staff professional learning community focused on issues of equity and inclusivity, including best practices for inclusive teaming in our courses [25]; (3) emphasizing the professional development of international students in undergraduate programs, including establishing a more inclusive School culture for this cohort; (4) working to better understand the overall climate and culture of the School, especially in relation to undergraduate student progression towards degree completion (or conversely loss of students from programs) and student identity formation [26, 27, 28]; and (5) 
continuing to establish systems and a culture for faculty and staff that recognize and reward lesstraditional work that values and contributes to the advancement of diversity, equity, inclusion, social justice, student success, and school community [29].

At the University of San Diego, the RED team includes the engineering leadership team with the Dean as the PI and coPIs including the Associate Dean and Chairs of General, Industrial and Mechanical Engineering. "Developing Changemaking Engineers” aims to prepare students to innovate engineering solutions within a contextual framework that embeds humanitarian, sustainable and social justice approaches with technical engineering skills. This requires an enhanced curriculum with a focus on student teamwork, a greater consideration of social context, improved communication with diverse constituents, and reflection on an ethical understanding of their decisions and solutions. Effective faculty members need to mirror these values and skills in their instruction and mentoring. Efforts have begun to reimagine the "engineering canon” which requires a shift from positioning engineering as a purely technical endeavor to framing it as socio-technical. We are developing a new General Engineering program that incorporates this perspective [30]. In addition, we are developing modules that emphasize the sociotechnical nature of engineering for traditional courses including Heat Transfer [31], Materials Science [32], and Operations Research [33], as well as newer courses such as User-Centered Design, Engineering and Social Justice [34], and Engineering Peace [35, 36]. Our industry partners have led the creation of an "Industry Scholars" program for first and second year engineering students to develop professional skills through workshops, field trips, internships, and interactions with professional engineers [37].

\section{Cohort 2}

At Boise State University, the RED team is building a Computer Science Professionals Hatchery that integrates ethics and social justice in agile Hatchery Units to promote a more inclusive culture and prepare students to work effectively on software development teams and be advocates for change in their future careers. Hatchery Units have been developed and taught that address foundational values in computer science, navigating computer systems, agile development, an introduction to database systems, and technical interviewing. The foundational values course helps students develop a framework for understanding issues of ethics and social justice in computer science, and these values and ideas are integrated into the more technically focused hatchery units and several traditional courses that are part of the required undergraduate computer science curriculum. A critical aspect of this project involves understanding the effects of these changes on the experiences of undergraduate students, particularly women and underrepresented minority students, and how deeply integrating ethics and social justice in a computer science curriculum can create a more welcoming and supportive computer science community. We are using multiple methods of exploring the effects of these changes, including surveys, interviews with students and faculty, and social network analysis. Next steps on the project will involve exploring and implementing ways to build community through increasing collaboration among students in different years in the curriculum.

At Rowan University, the RED team is known as RevED. RevED stands for Revolutionizing Engineering Diversity [38]. RevEd has short term goals that include an increase in social and cultural capital by developing more inclusive curriculum and admission standards. The program 
has long term goals that include increased recruitment and retention of diverse students through peer mentoring and curriculum reform as well as propagation of program elements to other institutions. A major goal RevED aims to accomplish is increasing underrepresented minority student representation in the Civil and Environmental Engineering Department by fifty percent and retain ninety-five percent of all students. In order to increase student diversity, RevED is looking to change admission criteria for first year and transfer students to promote diversity. A detailed evaluation of past admissions data was done to come up with new criteria. The new adopted criteria is a holistic evaluation process and less emphasis on standardized test scores. In addition, there has been significant cultural changes in the department including an enhanced perception and understanding of diversity among students, faculty, and administrators. A tiered peer mentoring program to service first year and transfer students and juniors and seniors has also been implemented. Faculty have also participated in teaching workshops and have been in the process of revising course content and incorporating inclusive teaching practices in all Civil and Environmental Engineering courses. In addition, students' engineering identity is developed by showcasing diverse professionals. These efforts are being widely disseminated using a dynamic website and other social media aids in addition to traditional methods of dissemination such as workshops, presentations and publications. Along with curriculum changes and changes in recruitment and retention practices, RevED also intends to change faculty evaluation practices and reward faculty that implement inclusive practices in their curriculum. More information about this project is available [39, 40].

At Virginia Tech, the goal of the RED grant is to transform the Bradley Department of Electrical and Computer Engineering so that it attracts a more diverse range of students and prepares them for a wider variety of careers. The transformation is based upon changing the department from having two separate curricular paths, electrical engineering and computer engineering, to having multiple pathways that enable students to choose from a variety of concentrations. Students will also have greater opportunities for open-ended design experiences throughout all four years of the program, including projects that will serve as outreach opportunities to K-12 students in underserved communities. A key aspect of the project is using threshold concepts—concepts that are integrative and transformative, and that are the basis for "thinking like an engineer"-as a lens for faculty, students, and alumni to engage in a participatory design process for changing departmental culture [41, 42]. An integral piece of the effort is having faculty, staff, and students participate in the re-design of the program, giving them ownership of the changes enabled by the grant and ensuring that the changes are sustainable beyond the grant's five-year term. To that end, the co-PIs have provided a variety of opportunities for department stakeholders to engage with the grant effort, including individual interviews with our social scientists to establish a baseline of the departmental culture, focus groups with our engineering education expert to explore threshold concepts across the entire breadth of the curriculum, and working groups of faculty and advising staff to design a new program structure with multiple pathways and to create instructional modules for the base courses in the program. To help faculty think in terms of students' perspectives on the program, the project is using the design approach of personas [43] — archetypes of potential students - to keep the focus of the changes on students' backgrounds and desires. The new program structure consists of a base of six courses for all students in the program, followed by primary and secondary concentrations (seven courses and three courses respectively) from a variety of technical specialties in ECE. Students will also have the option defining their own secondary concentrations rather than choosing one of the defined 
secondary concentrations. At the time of this writing (January 2018), the new program structure has been approved by the faculty, the paperwork for university approval of the structure is being prepared, and planning is underway for implementing the changes in the fall semester of 2018. More information about this project is available [44].

\section{Cohort 3}

At Georgia Tech, our vision is to revolutionize engineering education by creating engineers who are capable of realizing the inclusion dividend. Our work is grounded in two significant theoretical frameworks: optimal distinctiveness theory and human social systems theory. Optimal distinctiveness theory argues that people need to feel they belong and that they are valued for their uniqueness. Diversity efforts promote distinctiveness but often fail in achieving, for the minority member, a sense of belonging. To achieve our vision we will 1) establish a pedagogical incubator with a diverse collection of students, faculty, industry engineers, and learning scientists that will support the development of novel inclusive classroom practices, 2) iteratively hatch, implement and evaluate classroom activities and strategies that help students and faculty recognize the inclusion dividend and translate that recognition into inclusive interactive strategies, and 3) transform the departmental culture such that the inclusion dividend is embraced and enacted through inclusive interactions and practices evidenced one-on-one, in teams, in the classroom, in the research labs, and in department policies and procedures.

\section{RED Community}

\section{REDCON}

In establishing the RED program, NSF envisioned the emergence of a national cohort of change leaders [45]. With 19 RED teams, the national change leader cohort (called REDCON for RED Consortium) includes more than 150 people. REDCON activities include collaborative or crossteam dissemination of work, regular conference calls, and information exchange internal to the group and with external stakeholders. As RED teams mature in their work, they increasingly share expertise with each other, produce publications and presentations (traditional dissemination), engage with non-traditional audiences (e.g., non-STEM professional communities), produce artifacts and outcomes consistent with their goals, and reach milestones identified for their individual projects. The teams share common challenges and creative solutions. For example, nearly every RED team has noted challenges of some kind relating to community development, meaning working with their school's leadership, creating faculty buyin, or communicating with students, to name a few examples. By openly sharing these challenges, REDCON members receive suggestions that emerge from the real experiences of their REDCON colleagues (for example, one team discovered significant motivation to participate in RED team activities when faculty learned that they retained responsibility for their class content, while another team made progress by redefining success to mean cross-course collaboration).

The RED-funded teams are united in their commitment to the goals of the program. Although they enact the process of reaching those goals differently, the varied experiences of the teams contribute to a strong information base regarding successful change practices. For example, REDCON now includes two small private institutions. In contrast, several REDCON member team belong to universities classified as doctoral universities/highest research. The lessons these groups learn about accomplishing change will help determine how important are factors such as faculty reward systems, work-life balance, and student demographic contexts. Through their 
similarities (e.g., common purpose of improving diversity and inclusion) and their differences (e.g., the pedagogical, organizational, and curricular approaches they employ), we will learn about barriers and drivers of large scale change efforts. The information produced by the RED teams will serve higher education, and engineering education in particular, by creating a set of models for change.

\section{REDPAR}

NSF funded the collaborative effort REDPAR (for RED Participatory Action Research), composed of two partners: Making Academic Change Happen (MACH) from Rose-Hulman Institute of Technology and Center for Evaluation \& Research in STEM Equity (CERSE) from University of Washington. REDPAR facilitates the activities of REDCON, supports skills advancement in change among REDCON members, and performs research that crosses the consortium [46]. One important activity of REDPAR relates to its commitment to action research: we seek to answer research questions (accomplished primarily by CERSE) that then inform REDCON activities (accomplished primarily by MACH). Recent research has focused on the strategies that RED teams use to develop or inhibit shared vision among members of the team and with stakeholders, and how shared vision influences the teams' activities and goal attainment. Major results include that some teams found success in developing shared vision with creative incentives (e.g., from a focus group: “teaching will be fun”), culturally-relevant evidence (e.g., interviews with industrial board members helped shape curriculum changes), and intentionally inviting naysayers to contribute. Teams that created high levels of shared vision intentionally used collective work, collaboration on problems, and formative communication (rather than informational communication) [47]. Research relating to successful change is ongoing, now examining the partnerships that teams are creating and how their work follows or does not follow models of academic partnerships [e.g., 48]. These research results contribute to the development of REDCON activities and information-sharing. Teams are at various places in their project, represented by both year of award and success of the efforts, and their needs and challenges vary. REDPAR broadly shares research results and research-informed strategies to the benefit of all REDCON members.

Acknowledgements - This material is based upon work supported the United States National Science Foundation (NSF) under Grants EEC- 1519438, 1519453, 1519339, 1519467, 1540042, 1540072, 1623189, 1623067, 1632053, and 1730262. 


\section{References}

1 S. M. Lord, E. J. Berger, N. N. Kellam, E. L. Ingram, D. M. Riley, D. T. Rover, N. Salzman, and J. D. Sweeney, "Talking about a Revolution: Overview of NSF RED Projects," Proceedings of the 2017 ASEE Conference, Columbus, OH, June 2017.

2 J. Martin, private communication, January 19, 2018.

3 S. Jordan and M. Lande, “Additive innovation in design thinking and making," International Journal of Engineering Education, vol. 32, no. 3B, pp. 1438-1444, 2016.

4 A. McKenna., N. Kellam, M. Lande, S. Brunhaver, S. Jordan, J. Bekki, A. Carberry, and J. London, "Instigating a Revolution of Additive Innovation: An Educational Ecosystem of Making and Risk Taking," Proceedings of the 2016 ASEE Annual Conference, New Orleans, LA, June 2016.

5 N. Kellam, B. Coley, and A. Boklage, "Story of change-Using experience-based critical event narrative analysis to understand an engineering program's culture," Proceedings of the 7th Research in Engineering Education Symposium (REES), Bogota, Colombia, July 2017.

6 J. F. Wergin, "Beyond carrots and sticks: What really motivates faculty," Liberal Education, 87(1), 2001.

7 L. G. Bolman and T. E. Deal, "Leadership and management effectiveness: A multi-frame, multi-sector analysis," Human Resource Management 1, vol. 30, no. 4, pp. 509-34, 1991.

8 M. Borrego and C. Henderson, "Increasing the use of evidence-based teaching in STEM higher education: A comparison of eight change strategies,” Journal of Engineering Education, vol. 103, no. 2, pp. 220-252, 2014.

9 D. R. Denison and A. K. Mishra, "Toward a theory of organizational culture and effectiveness," Organization Science, vol. 6, no. 2, pp. 204-23, 1995.

10 J. V. Gallos (ed.) Organization development: A Jossey-Bass Reader, San Francisco, Jossey-Bass, 2006.

11 P. T. Terenzini and R. D. Reason, "Parsing the first year of college: A conceptual framework for studying college impacts," in Association for the Study of Higher Education, Philadelphia, 2005.

12 A. A. Maciejewski, Z. Byrne, T. W. Chen, A. Cook, G. Dangelmayr, M. A. De Miranda, A. Leland, B. Notaros, M. D. Reese, A. Rosales, T. J. Siller, and J. Weston, "Revolutionizing Engineering Departments at Colorado State University and Beyond," AAAS/NSF Envisioning the Future of Undergraduate STEM Education: Research and Practice, Washington, DC, April 27-29, 2016.

13 A. A. Maciejewski, T. W. Chen, Z. S. Byrne, M. A. de Miranda, L. B. Sample McMeeking, B. M. Notaros, A. Pezeshki, S. Roy, A. M. Leland, M. D. Reese, A. H. Rosales, T. J. Siller, R. F. Toftness, and O. Notaros, "A Holistic Approach to Transforming Undergraduate Electrical Engineering Education,” IEEE Access, Special Section on Innovations in Electrical and Computer Engineering Education, vol. 5, no. 1, pp. 8148-8161, Dec. 2017.

14 J. W. Weston, S. G. Manning, Z. S. Byrne, K. A. Cave, and A. A. Maciejewski, "Organizational change cynicism and job engagement," The 32nd Annual Conference of the Society of Industrial and Organizational Psychology, Orlando, FL, April 27-29, 2017.

15 J. W. Weston, Z. S. Byrne and A. A. Maciejewski, "Characteristics of learning organizations in an engineering academic unit," European Association of Work and Organizational Psychology, Dublin, Ireland, May 17-20, 2017.

16 B. M. Notaros, R. McCullough, P. S. Athalye, and A. A. Maciejewski, "Using Conceptual Questions to Assess Class Pre-Work and Enhance Student Engagement in Electromagnetics Learning Studio Modules," Proceedings of the 2017 ASEE Annual Conference, Columbus, OH, June 25-28, 2017.

17 T. Chen, A. A. Maciejewski, B. Notaros, A. Pezeshki, and M. D. Reese, "Mastering the core competencies of electrical engineering through knowledge integration," Proceedings of the 2016 ASEE Annual Conference, New Orleans, LA, June 26-29, 2016.

18 T. Chen, B. M. Notaros, A. Pezeshki, S. Roy, A. A. Maciejewski, and M. D. Reese, "Knowledge Integration to Understand Why," Proceedings of the 2017 ASEE Annual Conference, Columbus, OH, June 25-28, 2017.

19 Y. Liu, A. Pezeshki, S. Roy, B. M. Notaros, T. Chen, and A. A. Maciejewski, "Why Math Matters: Demonstrating the Relevance of Mathematics in ECE Education," Proceedings of the 2017 ASEE Annual Conference, Columbus, OH, June 25-28, 2017.

20 B. M. Notaros, R. McCullough, S. B. Manic, and A. A. Maciejewski, "Introducing MATLAB-Based Instruction and Learning in the Creativity Thread of a Novel Integrated Approach to ECE Education," Proceedings of the 2017 ASEE Annual Conference, Columbus, OH, June 25-28, 2017. 
21 A. Rosales, A. Leland, O. Notaros, R. Toftness, T. Siller, M. De Miranda, A. Cook, M. D. Reese, Z. Byrne, J. Weston, and A. A. Maciejewski, "Preliminary work on weaving professionalism throughout the engineering curriculum," Proceedings of the 2016 ASEE Annual Conference, New Orleans, LA, June 26-29, 2016.

22 D. Rover, M. Mina, D. Jacobson, P. Jones, J. Zambreno, A. A. Maciejewski, T. W. Chen, Z. S. Byrne, M. A de Miranda, L. B. Sample McMeeking, B. M. Notaros, A. H. Rosales, T. J. Siller, M. Reese, A. Leland, L. McNair, T. Martin, and M. Wisnioski, "Impacting Society through the Responsible Development of Technologies and Systems," special session on Catalyzing Collaborative Conversations, 2016 IEEE Frontiers in Education (FIE) Conference (FIE), Erie, PA, October 2016.

23 J. D. Sweeney, M. Koretsky, M. Bothwell, D. Montfort, S.B. Nolen, C. Kelly and S. Davis. "Re-Situating the Professional Formation of Engineering Identity," Proceedings of the 2018 ASEE Annual Conference, Salt Lake City, UT, June 2018.

24 M. Koretsky, D. Montfort, S. Nolen, M. Bothwell, S. Davis and J. Sweeney. "Towards A Stronger Covalent Bond: Pedagogical Change for Inclusivity and Equity,” Chemical Engineering Education, vol. 52, no. 2, pp. 117-127, 2018.

25 N. Mallette, C. Kelly and M. Bothwell, "Work-in-Progress: Developing an Integrated Curriculum-Wide Teamwork Instructional Strategy,” Proceedings of the 2018 ASEE Annual Conference, Salt Lake City, UT, June 2018.

26 S.C. Davis, E.C. Moise, N. Cheon and S.B. Nolen, "Investigating Student Perceptions of an Engineering Department's Climate: The Role of Peer Relations,” Proceedings of the 2017 ASEE Annual Conference, Salt Lake City, UT, June 2018.

27 S.C. Davis, S.B. Nolen, N. Cheon and E.C. Moise, "Investigating Factors Related to Disciplinary Identification and Persistence in Undergraduate Engineering Education,” American Educational Research Association (AERA) Annual Meeting, New York City, NY, April 2018.

28 A. Godbole, B. Miller, M. Bothwell, S. Davis, D. Montfort and S.B. Nolen, "Engineering Students' Perceptions of Belonging Through the Lens of Social Identity," $1^{\text {st }}$ Annual Conference of CoNECD Collaborative Network for Engineering and Computing Diversity, Arlington, VA, April/May 2018.

29 J. D. Sweeney, M. Bothwell, D. Montfort, S. Nolen, S. Davis, and M. Koretsky, "Motivating and Engaging Faculty in Cultural and Curricular Transformation of a Multidisciplinary Engineering School," Proceedings of the 2017 ASEE Annual Conference, Columbus, OH, June 2017.

30 D. A. Chen and G. D. Hoople, "Contextualizing a New General Engineering Curriculum in the Liberal Arts," Proceedings of the 2017 ASEE Annual Conference, Columbus, OH, June 2017.

31 E. Reddy, B. Przestrzelski, S. M. Lord, and I. Khalil, "Introducing Social Relevance and Global Context into the Introduction to Heat Transfer Course,” Proceedings of the 2018 ASEE Annual Conference, Salt Lake City, UT, June 2018.

32 B. Przestrzelski, E. Reddy, and S. M. Lord, "Integrating Social with Technical: "Bring in your Trash" module for a Materials Science Class,” Proceedings of the 2018 ASEE Annual Conference, Salt Lake City, UT, June 2018.

33 R. Olson and A. Acero, "Introducing Changemaking Engineering into an Operations Research Course: Some Unexpected Results,” Proceedings of the 2018 ASEE Annual Conference, Salt Lake City, UT, June 2018.

34 J. A. Mejia, O. Dalrymple, D. Chen, and S. M. Lord, "Revealing the Invisible: Conversations about -Isms and Power Relations in Engineering Courses,” Proceedings of the 2018 ASEE Annual Conference, Salt Lake City, UT, June 2018.

35 G. D. Hoople and A. Choi-Fitzpatrick, "Engineering Empathy: A Multidisciplinary Approach Combining Engineering, Peace Studies, and New Technology,” Proceedings of the 2017 ASEE Annual Conference, Columbus, OH, June 2017.

36 E. Reddy, G. D. Hoople, and A. Choi-Fitzpatrick, "Work-in-Progress: A Study of Collaborative Embodiment Through Gesture Analysis of Students in "Drones for Peace," a Team-Based Multidisciplinary Undergraduate Course," Proceedings of the 2018 ASEE Annual Conference, Salt Lake City, UT, June 2018.

37 B. Przestrzelski, L. A. Perry, and C. A. Roberts, "The Industry Scholars Program: An Immersive Professional Experience for Undergraduates,” Proceedings of the 2018 ASEE Annual Conference, Salt Lake City, UT, June 2018.

38 D. Macey, D. Zeppilli, T. Forin, and B. Sukumaran, RevEd Website, http://reved.rowan.edu (last accessed January 15, 2018)

39 B. Sukumaran, H. Hartman, S. Farrell, R. Dusseau, K. Jahan, P. Bhavsar, and T. Forin, "Rethinking Engineering Diversity, Transforming Engineering Diversity," Proceedings of the 2017 ASEE Annual Conference, Columbus, OH, June 2017. 
40 S. Farrell, R. Dusseau, and T. Forin, "WIP Developing Multiple Strategies for an Inclusive Curriculum in Civil Engineering," Proceedings of the 2017 ASEE Annual Conference, Columbus, OH, June 2017.

41 D. Reeping, L. D. McNair, S. R. Harrison, R. B. Knapp, L. F. Lester, T. Martin, A. Y. Patrick, and M. Wisnioski, "How are Threshold Concepts Applied? A Review of the Literature," Proceedings of the 2018 ASEE Annual Conference, Columbus, OH, June 25-28, 2017.

42 D. Reeping, L. D. McNair, M. Wisnioski, A. Y. Patrick, T. Martin, L. Lester, B. Knapp, and S. Harrison, "Using threshold concepts to restructure an electrical and computer engineering curriculum: Troublesome knowledge in expected outcomes," IEEE Frontiers in Education Conference (FIE), October 2017, Indianapolis, IN, pp. 1-9.

43 LUMA Institute, Innovating for People: Handbook of Human-Centered Design Methods, Pittsburgh, PA, 2012.

44 Virginia Tech, "Faculty receive grant to transform undergraduate engineering education," https://vtnews.vt.edu/articles/2016/07/icat-engineeringeducation.html (last accessed 25 January 2017).

45 National Science Foundation, IUSE/Professional formation of engineers: Revolutionizing engineering and computer science departments (IUSE/PFE: RED) solicitation 17-501, 2016. https://www.nsf.gov/pubs/2017/nsf17501/nsf17501.htm

46 E. L. Ingram, E. Litzler, C. Margherio, and J. M. Williams, "Learning to Make Change by Revolutionizing Departments: Initial Team Experiences," Proceedings of the 2017 ASEE Annual Conference, Columbus, OH, June 2017.

47 C. Margherio, E. Litzler, and K. Doten-Snitker, "Developing a Shared Vision for Change: New results from the Revolutionizing Engineering Departments Participatory Action Research,” Proceedings of the 2017 ASEE Annual Conference, Columbus, OH, June 2017.

48 P. L. Eddy and M. J. Amey, Creating Strategic Partnerships: A Guide for Educational Institutions and Their Partners. Stylus Publishing, Sterling, VA, 2014. 